$5-2017$

\title{
The Relationship Between Parenting Style and Self-Regulation in Early Childhood
}

Madeline Newman

Dominican University of California

https://doi.org/10.33015/dominican.edu/2017.HONORS.ST.19

Survey: Let us know how this paper benefits you.

\section{Recommended Citation}

Newman, Madeline, "The Relationship Between Parenting Style and Self-Regulation in Early Childhood" (2017). Honors Theses. 14.

https://doi.org/10.33015/dominican.edu/2017.HONORS.ST.19

This Honors Thesis is brought to you for free and open access by the Student Scholarship at Dominican Scholar. It has been accepted for inclusion in Honors Theses by an authorized administrator of Dominican Scholar. For more information, please contact

michael.pujals@dominican.edu. 


\title{
The Relationship Between Parenting Style and Self-Regulation in Early Childhood
}

\begin{abstract}
Research demonstrates the significance of the quality and quantity of caregiver guidance in the rearing of children. Many empirical studies find a correlation between social and developmental psychology and child rearing (Karreman et al., 2006). An important component of social-emotional development is a child's ability to self-regulate--controlling bodily impulses, managing strong emotions, and maintaining focus and attention (Eisenberg, 2005). Children of authoritative parents have well-regulated emotions, respond well to difficult tasks, and exhibit developed social skills and happy and spirited dispositions; whereas, children of authoritarian and permissive parents lack many of those skills (Baumrind, 1971). Studies also show that cultural background and preschool attendance may also influence the development of self-regulation (e.g., LeCuyer et al., 2011; Alejandro et al, 2016). Sixty-four parents completed the Parenting Style and Dimensions Questionnaire and the Children's Behavior Questionnaire. Results indicated that authoritative parenting is positively correlated with enhanced self-regulation, and authoritarian and permissive parenting are associated with decreased self-regulation. Further results showed that ethnicity did not play any role in parenting style or child self-regulation, and neither did preschool attendance. With this research, it becomes crucial to emphasize quality care for children during early development.
\end{abstract}

Keywords: early childhood, parenting styles, self-regulation

\section{Document Type}

Honors Thesis

Degree Name

Bachelor of Arts

Department

Psychology

First Reader

Veronica Fruiht, PhD

Second Reader

Mojgan Behmand, PhD

\section{Keywords}

parenting style, self-regulation, early childhood, authoritative, authoritarian, permissive

\section{Subject Categories}

Child Psychology | Developmental Psychology | Psychology 
The Relationship Between Parenting Style and Self-Regulation in Early Childhood Madeline Newman

Dominican University of California 


\begin{abstract}
Research demonstrates the significance of the quality and quantity of caregiver guidance in the rearing of children. Many empirical studies find a correlation between social and developmental psychology and child rearing (Karreman et al., 2006). An important component of socialemotional development is a child's ability to self-regulate — controlling bodily impulses, managing strong emotions, and maintaining focus and attention (Eisenberg, 2005). Children of authoritative parents have well-regulated emotions, respond well to difficult tasks, and exhibit developed social skills and happy and spirited dispositions; whereas, children of authoritarian and permissive parents lack many of those skills (Baumrind, 1971). Studies also show that cultural background and preschool attendance may also influence the development of selfregulation (e.g., LeCuyer et al., 2011; Alejandro et al, 2016). Sixty-four parents completed the Parenting Style and Dimensions Questionnaire and the Children's Behavior Questionnaire. Results indicated that authoritative parenting is positively correlated with enhanced selfregulation, and authoritarian and permissive parenting are associated with decreased selfregulation. Further results showed that ethnicity did not play any role in parenting style or child self-regulation, and neither did preschool attendance. With this research, it becomes crucial to emphasize quality care for children during early development.
\end{abstract}

Keywords: early childhood, parenting styles, self-regulation 
The Relationship Between Parenting Style and Self-Regulation in Early Childhood Within the last century, the rise of psychology as seen through a scientific lens has caused increased interest in the rearing of children. Developmental scientists began asking questions, like how should children be raised? What role does parenting play in a child's development? Are certain parenting practices harmful? While there is near universal agreement that parents have influence over their children's developmental outcomes, recent studies have begun to focus on specific parenting styles, and their associated outcomes.

Baumrind (1966) was a pioneer of contemporary views on parenting. With Baumrind's categories of authoritative, permissive, and authoritarian styles of parenting, parents could be studied concurrently with the development of their children. Baumrind (1967) found that in western societies, parents who assert direct but reasonable expectations, raise children who exhibit well developed social skills and positive, lively dispositions. However, when looked at cross-culturally, studies show that such findings are not universal (Darling \& Steinberg, 1993). A comprehensive review of the conceptualization of parenting styles distinguishes between parenting "styles" and "practices," and ultimately found that individuals from different ethnic and cultural backgrounds may operationalize Baumrind's parenting styles differently—such as parents having authoritarian beliefs, yet practicing authoritative behaviors. With this in mind, parenting style is best conceptualized as a context that moderates specific parenting practice on children (Darling \& Steinberg, 1993).

Studies find that parenting style is a strong predictor of cognitive and social-emotional developmental success in children. Eisenberg et al. (2005) found that positive parenting predicted high levels of regulation in children, which in turn correlated to low levels of externalizing problems, like physical aggression and stealing. Many such studies find the 
correlation between parenting style and a wide range of child developments and activitiesacademic success, social-emotional development, self-regulation, delinquency, and substance abuse (e.g., Steinberg et al., 1991; Steinberg et al., 1992; Cho, Kogan, \& Brody, 2016; ZarraNezhad, 2014). This paper aims to examine the relationship between parenting style and important social-emotional and behavioral outcomes in early childhood. Moreover, we will evaluate the predicting factors of self-regulation in early childhood (ages three to seven), as seen through the context of parenting styles and practices.

\section{A Typology of Parenting Styles}

Parenting style is often defined by three different characterizations: "the goals toward which socialization is directed; the parenting practices used by parents to help children reach those goals; and the parenting style, or emotional climate, within which socialization occurs" (Darling \& Steinberg, 1993, 448). Baumrind (1966) originally differentiated parenting style as either permissive, authoritarian, or authoritative. Permissive parenting (high warmth, low demandingness) is characterized by non-punitive, accepting, and affirming actions in response to children's behavior. This style is grounded on children regulating the majority of their actions, and receiving little to no exercise of control from parents. The parents present themselves to their children as resources, but not as ideal models for behavior. Much the opposite of permissive parenting, authoritarian parenting style is characterized by complete control (low warmth, high demandingness). Authoritarian parents believe children should emulate the actions, conduct, and beliefs of their parents. When exhibiting behavior that conflicts with those standards, punitive measures are taken to correct the misconduct. Baumrind (1967) ultimately defined authoritative parenting as the prevailing standard western standard (high warmth, high demandingness). The authoritative style finds a balance between strict expectations and reasonable independence. 
Parents value the perspective of their children, and take that into account when setting and explaining policy. The relationship is characterized as give and take, but is fundamentally determined by parents (Baumrind, 1966, 1967, \& 1971). From here, Baumrind outlined the correlations between parenting style and child development_-findings of which have been further validated in subsequent studies.

\section{The Associated Outcomes of Parenting Style}

There is an array of research on outcomes associated with parenting styles. Topics of academic success, deviant behavior, and social-emotional outcomes are all important areas of inquiry. Researchers have considered these outcomes both in younger and older children, and attempted to differentiate between parenting styles and their respective association with negative or positive outcomes. However, within the array of literature, studies concerning parenting style and academic outcomes, and parenting style and adolescent social-emotional outcomes, far outweigh the research concerning parenting style and early childhood social-emotional outcomes. Baumrind (1966, 1967, \&1971) and additional researchers (e.g., Karreman et al., 2006; Eisenberg, 2005; LeCuyer et al., 2011) offer a basis for filling this gap, and additional research replicating these findings could offer further validation. In order to build on these studies, further research is needed to reaffirm the association between parenting style and early childhood social-emotional outcomes.

Baumrind (1966, 1967, \&1971) found that differing parenting styles resulted in differing outcomes in early childhood, especially within a social-emotional context. Social-emotional development is characterized by how children experience, express and manage emotions, as well as their ability to make positive and enriching relationships with others. Important aspects of social-emotional development include self-concept, self-esteem, self-regulation of emotions, 
social-competence, and development of empathy (Shaffer \& Kipp, 2013). Authoritarian parenting has been correlated to children with anxious, withdrawn, and unhappy behavior (Baumrind, 1971). Girls exhibited a tendency to give up when frustrated, whereas boys tended to become hostile. However, these children did well academically and were not likely to engage in socially unacceptable behaviors (i.e. drug use, gang activity, breaking the law; Baumrind, 1971). Children of permissive parents exhibited poor emotion control, socially unacceptable behaviors, low persistence when faced with challenges, and were defiant when their desires were opposed (Baumrind, 1971). In comparison to the other parenting styles, children of authoritative parents had well-regulated emotions, could respond well to difficult tasks, exhibited age-appropriate social skills, and had overall happy and spirited dispositions (Baumrind, 1971). Children of authoritarian and permissive parents had overall poor responses when reacting to frustrating and undesirable situations, whereas children of authoritative parents were able to regulate their emotions and respond appropriately — otherwise known as the facilitation of self-regulation.

Although there are many studies examining the effects of parenting style, many focus on middle childhood and adolescence, especially regarding the outcomes of academic success and anti-social behaviors (e.g., Steinberg et al., 1991; Steinberg et al., 1992; Cho, Kogan, \& Brody, 2016; Zarra-Nezhad, 2014). Some research examines parenting style effects on social-emotional development in later childhood, but there are fewer studies on the effects of parenting style on children in early childhood. Up and coming research and initiatives, such as California's "First 5" promotes the importance of the first five years in childhood, and a recent study found a significant correlation between high quality preschool services and later academic and life success (Ramey \& Ramey, 2004). Additionally, a 23-year long longitudinal study found that children's early-emerging behavior styles are the best indicator of future thoughts, feelings, and 
characteristics as adults (Capsi et al., 2003). Consequently, researchers began to question what factors influence the development of social-emotional skills. A large number of empirical studies have been published demonstrating the correlation between social and developmental psychology and child rearing (Uji, Sakamoto, Adachi, \& Kitamura, 2014). From here, researchers investigate how subsequent parenting styles, such as Baumrind's (1967) authoritative, authoritarian, and permissive styles, influence social-emotional development.

In order to decipher the importance of early childhood intervention and the qualities that play a significant role in academic success (attentiveness, organization, independence, eagerness to learn, ability to adapt to change, and persistence), further research is on parenting style and early childhood is crucial. Many of these academic qualities, which are also applicable in environments outside the classroom, find their roots in social-emotional development (Shaffer \& Kipp, 2013). Several studies support the importance of education in the development of selfregulation (Alejandro et al., 2016, Razza et al., 2015, \& Reynolds et al., 2014). Children who practice mindful yoga in preschool have been found to have higher self-regulation, suggesting that preschool is an important venue to practice and develop social-emotional skills (Razza et al., 2015). Another study found that full-day preschool attendance children, in comparison to partday attendance, scored higher on social-emotional development, language, and math (Reynolds et al., 2014) In particular, preschool attendance is a significant predictor of self-regulation in kindergarten (Alejandro et al, 2016).

\section{The Relationship Between Parenting Style and Self-Regulation}

The development of self-regulation is an integral aspect of a child's social-emotional maturation (e.g., Baumrind, 1971; Eisenberg, 2005). Self-regulation is defined as the ability to monitor and alter one's responses to a situation, through behaviors, thoughts, and emotions. It 
includes inhibiting first reactions, resisting distraction, and persisting on tasks even when they may be difficult or undesirable (Shaffer \& Kipp, 2013). Children are expected to learn to manage their impulses and emotions, and in turn use these skills to become functioning members of society. Social expectations for self-regulation may differ cross-culturally, and therefore the parenting practices employed may also differ (LeCuyer et al., 2011). However, regardless of gender, socio-economic status, age, or ethnicity, it can be agreed that in one way or another, parenting style has an influence on a child's development of self-regulation (Karreman et al., 2006).

Several studies have linked parenting style with children's ability to self-regulate (e.g. Baumrind, 1971, \& Eisenberg, 2005). Both maternal and paternal authoritative parenting style has significant positive effect on emotion regulation in adolescence, whereas permissive parenting style has significant negative effect on emotion regulation (Jabeen, Anis-ul-Haque, Riaz, 2013). An important aspect of self-regulation among younger children is effortful control (EC), or a child's ability to inhibit dominant responses, and in turn plan and activate subdominant responses such as repressing the urge to throw a tantrum when told 'no', and instead attempting to make a compromise. EC has been found to be a determining factor when evaluating the effects of parenting style of externalized behaviors (Eisenberg, 2005). Another study found that parental behavior and emotional tone appear to be especially influential on the EC development of child who positively approached novel experiences (Cipriano \& Stifter, 2010). Additionally, positive parenting (which has many roots in authoritative parenting) is a predictor of EC, which is turn predicts the low levels of externalizing problems - behaviors that are directed externally, such as physical aggression, disobeying rules, and cheating (Eisenberg, 2005). 
Piotrowski, Lapierre, and Linebarger (2013) found that parenting style is strongly associated with child self-regulation. Parents who exhibit nurturing practices that reinforce a child's autonomous self, but also remain consistent in expectations, have children who show well-developed self-regulation. They also found that parents who exert excess control, or notably minimal control, have children with poor self-regulation skills. An additional study (Crossley \& Buckner, 2012) found a correlation between maternal mental health, parenting practices, and child self-regulation. Mothers who exhibit negative mental health are subsequently prone to detrimental parenting practices, which then has a negative effect on their children's selfregulation (Crossley\& Buckner, 2012). Finally, a meta-analysis of 41 studies pertaining to parenting and self-regulation in preschoolers found that positive control (limit-setting activities with clear guidance and instruction) was associated with higher self-regulation (Karreman et al., 2006). Whereas, negative control (power-assertive activities, critical comments and coercive behaviors), was associated with lower self-regulation. Responsiveness, which is characterized by warm behavior and acceptance, was not significantly associated with self-regulation (Karreman et al., 2006).

\section{The Role of Culture in Understanding Parenting Style}

In response to contemporary research on parenting style outcomes, Baumrind's theory has undergone some reconceptualization. In her 1966 study of parenting styles, Baumrind ignored ethnic and cultural differences, choosing to omit individuals from diverse groups from her studies. When revisited (LeCuyer et al., 2011), it was found that when viewed through the lens of "white norms," the African-American families that Baumrind omitted tended to have primarily authoritarian attitudes. Interestingly, the most authoritarian of these families produced the most self-assertive and independent female children. However, in contrast to Baumrind's 
unpublished findings, a recent study found that in a within-group study of African-American mothers and their three-year-old children, higher levels of authoritarian attitudes were associated with lower levels of children's self-regulation — as seen in European-American families (LeCuyer et al., 2016). It is noteworthy that although African-American mothers themselves reported having more authoritarian attitudes than European-American mothers report, observational data finds that African-American mothers actually display authoritative behavior that is similar to European-Americans (LeCuyer et al., 2011). When comparing AfricanAmerican mothers' attitudes relative to those of other African-American mothers, more authoritative mothers raise children with more positive outcomes (LeCuyer at al., 2016). Findings such as these suggest that when obtaining data on parenting attitudes, AfricanAmerican mothers may report having authoritarian attitudes, yet display more authoritative behavior. One possible result of this effect is that of a misleading positive association between authoritarian attitudes and child self-regulation. Findings such as these suggest that when evaluating the effects of parenting style, one needs to consider the possible explanations for such correlations: cultural identity, the difference between parenting styles and practices, societal influence of gender roles, genetics, or task performance bias.

These considerations prompted the reconceptualization of parenting styles to include a distinction between parenting style (such as overall attitude to parenting), and actual parenting practices. Darling and Steinberg (1993) suggest that parenting style be conceptualized best as a context that moderates the influence of specific parenting practices on children. One must take into account that some parenting practices affect children differently, dependent on familial and cultural perspective. It is also important to note that although there is wide consensus that authoritative parenting produces more competent children, there is little research to explain why 
or how. Many perspectives, such as attribution and social learning theory offer interesting explanations about how this association might occur, but we are still lacking the empirical evidence necessary to allow us to judge why some parenting styles produce better outcomes (Darling \& Steinberg, 1993). When exploring the social-emotional outcomes of children, researchers are better able to differentiate between parenting styles, and pinpoint which practices are best utilized. Although it is difficult to ascertain why these associations occur, the continuation of parenting style research can further the evidence necessary to make definitive conclusions on social-emotional outcomes.

\section{Hypotheses}

Consistent with past research suggesting that parenting style has correlational influence on the development of specific social-emotional and behavioral functioning, I posited the following hypotheses:

1a. The higher a parent scores on the authoritative parenting style scale, the higher scores of self-regulation his/her child will present.

1b. The higher a parent scores on the authoritarian parenting style scale, the lower scores of self-regulation his/her child will present.

1c. The higher a parent scores on the permissive parenting style scale, the lower scores of self-regulation his/her child will present.

2. European-American children will exhibit stronger associations between self-regulation and authoritative parenting, as compared to African-American, Asian-American, and HispanicAmerican children.

3. Children who attend preschool will exhibit higher self-regulation scores, as compared to children who do not attend preschool. 


\section{Method}

\section{Participants}

This study utilized a sample of 64 adults recruited from preschools and social media. Eligibility for this study required being a parent of a child between the ages of 3 and 7 years. The composition of the sample was $89.1 \%$ women. Participants ranged in age from 28 to 60 with a mean age of $37.59(S D=6.23)$. The majority of the sample identified as Caucasian $(92.2 \%)$, followed by Hispanic (3.1\%), Other (4.7\%). The educational status of the sample was primarily college educated $(39.1 \%)$, with $1.6 \%$ of the sample having attended only $8-12$ years of grade schooling, $21.9 \%$ having attended some college, $12.5 \%$ having attended some graduate school and $25 \%$ of the sample reported having obtained a graduate or professional degree. The majority of the sample had two children (40.6\%), followed by three children $(21.9 \%)$, one child (20.3\%), and then four or more children (17.2\%). Children of the participants ranged in age from 3 to 7 with a mean age of $5.13(\mathrm{SD}=1.351)$. The composition of children was $50 \%$ female, $78.1 \%$ identified Caucasian, and of children younger than five-year-old, 63.6\% attended preschool. All participants were notified of the voluntary nature of this study, and the study protocol was approved by the university's Institutional Review Board.

\section{Measures}

Parenting styles and dimensions questionnaire: short form. Robinson's parenting style and dimensions questionnaire (PDSQ), uses the primary parenting styles typologies, as proposed by Baumrind (1971): authoritarian (high control, low warmth), permissive (low control, high warmth), and authoritative (high control, high warmth). The PDSQ is a 32-item questionnaire which assessed the style of parenting. Participants responded on a five point Likert scale, with one corresponding to 'never' and five corresponding to 'always' (Robinson, 
Mandleco, Olsen, \& Hart, 2001). In a review of psychometric properties of the PSDQ (based on 53 articles published between 1995 and 2012), Olivari, Tagliabue, and Confalonieri (2013) deemed its validity adequate, although tested in few studies.

Children's behavior questionnaire: short form. Rothbart's children behavior questionnaire (CBQ), a measure of children's temperament, was operationalized to determine children's self-regulation. Five scales were utilized, including activity level, attentional focusing, impulsivity, reactivity, and inhibitory control. The operationalized CBQ used 31 items, assessed on a seven point Likert scale, with one corresponding to 'extremely true of your child' and seven corresponding to 'extremely untrue of your child'. The measure demonstrated both satisfactory consistency and validity, and exhibited longitudinal stability compared to that of the standard CBQ (Putnam \& Rothbart, 2006). The measure has been previously operationalized and validated to measure effortful control (Backer-Grøndahl, Nærde, Ulleberg, \& Janson, 2016).

\section{Procedure}

Participants completed a survey package consisting of demographic questions and questionnaires designed to assess parenting style and children's level of self-regulation. The survey was distributed primarily through email, as well as through links posted on social media. The link directed individuals to a secure survey-based website.

\section{Results}

To test hypothesis 1, a Pearson $\mathrm{r}$ correlation coefficient was calculated for the relationship between participants' authoritative parenting score and their child's self-regulation score. As shown in table 1 and figure 1, a positive correlation was found $(r(62)=.378, p<.01)$, indicating a significant linear relationship between the two variables. Parents with higher authoritative scores tend to have children with higher self-regulation scores. Similarly, when 
comparing authoritarian parenting and self-regulation, negative correlation was found $(r(62)=-$ $.320, p<.01$ ), indicating a significant inverse relationship between the two variables (table 2). Parents with high authoritarian scores tend to have children with lower self-regulation scores. When correlating permissive parenting (table 1) and self-regulation, a negative significant correlation was found $(r(62)=-.293, p<.05)$. Parents with high permissive parenting scores tend to have children with lower self-regulation. Specific parenting subgroup correlations can be found in table 1 and table 2.

To test hypothesis 2, a factorial ANOVA was calculated examining the relationship between participants' identified ethnicity, authoritative scores, and their children's selfregulation scores. Authoritative parenting scores were divided into four quartiles and ethnicity was categorized as Caucasian and non-Caucasian due to lack of variability in ethnicity. The main effect for ethnicity was not significant $(F(3,60)=3.54, p>.05)$. However, as seen in the Pearson $\mathrm{r}$ correlation, the main effect for parenting style was significant $(F(2,61)=5.29, p<.01)$. See figure 2 for a visual representation. Finally, authoritative parenting style and ethnicity do not significantly interact to predict child self-regulation. The impact of parenting style on selfregulation does not differ between individuals of different ethnicity.

Finally, to test hypothesis 3 , an independent samples t test was calculated comparing the mean score of child self-regulation to preschool attendance or absence. No significant difference was found $(t(20)=-.841, p>.05)$. The mean self-regulation of children who attended preschool $(M=4.43, \mathrm{SD}=.9)$ was not significantly different from the mean of children who did not attend preschool $(M=4.1, \mathrm{SD}=.81)$. 


\section{Discussion}

This study set out to investigate the correlation between parenting style and selfregulation in early childhood. Preliminary literature review research shows that authoritative parenting, which is defined by high control and high warmth, is correlated with children with positive social-emotional outcomes (Baumrind, 1967). Similarly, authoritarian parenting (high control and low warmth) and permissive parenting (low control and high warmth) is associated with children with lower self-regulation scores. The present study furthered this research and ascertained that authoritative parenting is correlated with higher child self-regulation. A similar, inverse, relationship was found with authoritarian parenting and permissive parenting. Additionally, no interaction was found between ethnicity and parenting style in predicting selfregulation. Nor was there a difference in self-regulation between preschool attendance and nonattendance.

Particular subscales of the authoritative and authoritarian scale were significant predictors of child regulation, while others were not. For example, in the authoritative parenting scale, there was a significant correlation between parental regulation and child self-regulation, and parental autonomy granting and child self-regulation. This suggests that the more regulation, reasoning, and democratic participation parents exhibit to their children, the higher self-regulation those children are reported to have. However, the third subgroup of authoritative parenting, warmth and support, was not significantly correlated to self-regulation. This is congruent with Karreman et al. (2006), who found through a meta-analysis that positive control (characterized by limitsetting activities and the use of clear guidance and instructions) is positively associated with selfregulation, while responsiveness (warmth and acceptance) has no significant correlation.

In the authoritarian scale, parental verbal hostility and non-reasoning, punitive actions, 
were significantly correlated with lower child self-regulation. Negative control (power-assertive activities, coercive behaviors and hostility) has been shown by past research to be negatively associated with self-control (Karreman et al., 2006). Similar to authoritarian parenting, inconsistent and harsh parenting is associated with a multitude of deficient developmental outcomes (mostly through externalized behavior problems; Crossely \& Buckner, 2012). Hanley and Abell (2002), suggest that parenting is a crucial aspect of Maslow's (1948) hierarchy of needs, in that a parent's support in instrumental in a child eventually self-actualizing (realization of one's value and potential). However, the physical coercion from the authoritarian scale, was not significantly correlated to self-regulation outcomes. These findings could be a result of question phrasing, or even parental bias or reluctance when self-reporting, as seen in other studies (LeCuyer, 2011).

When calculating permissive scores, it was found to be significantly correlated to low child self-regulation. Although there were no subscales for the permissive category, and considerable fewer questions, these findings are congruent with other studies on self-regulation. Both Bernier et al. (2010) and Piotrowski et al. (2012) found that permissive parenting style is associated with lower regulatory skills in young children. These results suggest that parents who have a notable absence of parental control tend to have children with self-regulation deficits.

The present study had several limitations. Firstly, sample size was relatively small $(N=$ 64) in comparison to other studies about parenting style. More importantly, however, the sample was very homogenous. Ninety-two-percent of respondents identified as Caucasian, which greatly hindered testing the ethnicity interaction. Because of this lack of diversity, ethnicity was instead categorized with the more diverse child-ethnicity, and defined as either "Caucasian" or "nonCaucasian." In addition to the lack of diversity in the sample, ethnicity was measured with the 
items, "What is your ethnicity?" and "What is your child's ethnicity?" In order to capture culture, the study might have additionally included a cultural identity scale such as the Vancouver Index of Acculturation (Ryder et al. 2000). Although the present study already had a homogenous sample and a cultural identity scale may not have produced more accurate outcomes, future research would benefit from distinguishing between culture and ethnicity. A meta-analysis of parenting style outcomes in culturally diverse western nations found that depending on origin of country, different parenting styles had varying strength of association with behavioral problems and academic success (Pinquart \& Kauser, 2017). These results suggest that participants may not be accurately represented in the present study. Such as, responding "Hispanic" could place a participant in multiple categories, such as Mexico, Puerto Rico, and Spain, which have varying parenting style outcomes.

Additionally, there are several limitations that could account for the lack of correlation between preschool attendance and self-regulation, as otherwise seen in Alejandro et al. (2016). With such a homogenous sample, and a mean child age of five, there were only eight participants who did not send their children to preschool. Participants who had school-aged children could not be included when calculating self-regulation in respect to school attendance, as it the norm for children aged five and older to be attending school full-time. To correct this limitation, future research should seek parent participants from locations other than preschools, such as community centers, and summer recreation programs.

Future research should sample from populations of younger parents (aged 18-25), and look for a correlation between parenting style, parent age, and child self-regulation. The present study had a sample of participants with a mean age of 37. Research (Lewin et al., 2013) suggests that parental age, especially that of adolescent and emerging adult mothers, is associated with 
parenting behavior. Results indicated that the younger the mother, the more negative parenting behaviors were practiced (Lewin et al., 2013). Additionally, samples of older children (middle childhood and adolescence) would be compared to children in early childhood, examining the interaction of child age, parenting style, and child self-regulation. This would allow researchers to better understand how parental age affects parenting style, and if there is an interaction between parental age, child age, parenting style, and child self-regulation.

Future research should also consider alternative measures of parenting style and child self-regulation. The present study employed the use of self-report questionnaires, sent to participants electronically, to be completed at home. It would be beneficial to assess parenting style and child self-regulation through observational and interview measures, such as task completion, parental interviews and observations concerning parenting style. Examples of task completion measures include Head Toes Knees Shoulders (Ponitz et al., 2008) and the Copying Design Test (Obsborne et al., 1984), which both test inhibitory control and attentional focusing. With such measures, it would be easier to control for the timing of assessment, which may influence levels of tiredness and accuracy of responses. It may also control for participant bias--when self-reporting, parents' perceptions of themselves and their children may be positively or negatively biased (Stokes et al., 2011).

To conclude, the present study provides an analysis of parenting style and self-regulation outcomes in early childhood. Both authoritarian parenting and permissive parenting styles correlate with lower child self-regulation scores, whereas authoritative parenting is associated with higher self-regulation scores. However, neither ethnicity nor preschool attendance could be connected to self-regulation. This research contributes to the growing exploration of early childhood development, and suggests the importance of educating parents on the implications 
and outcomes that parenting style has on their children. Although secondary or tertiary caregivers were not assessed in this study, these results may have importance for professionals who work with children in care-giving environments. For now, this research proposes that parenting style and child self-regulation are intricately related. 


\section{References}

Alejandro, J. P., Leslie, A. M., Manley, B. C., Rivas, A. F., Wiltermood, D. M., \& Bainum, C. K. (2016). Preschool attendance as a predictor of self-regulation in kindergarteners. Psi Chi Journal of Psychological Research, 21(4), 222-229.

Backer-Grøndahl, A., Nærde, A., Ulleberg, P., \& Janson, H. (2016). Measuring effortful control using the Children's Behavior Questionnaire-Very Short Form: Modeling matters. Journal of Personality Assessment, 98(1), 100-109. doi:10.1080/00223891.2015.1056303

Baumrind, D. (1966). Effects of authoritative parental control on child behavior. Child Development, 37(4), 887-907. doi:10.2307/1126611

Baumrind, D. (1967). Child care practices anteceding three patterns of preschool behavior. Genetic Psychology Monographs, 75(1), 43-88.

Baumrind, D. (1971). Current patterns of parental authority. Developmental Psychology, 4(1, Pt.2), 1-103. doi:10.1037/h0030372

Baumrind, D., Larzelere, R. E., \& Owens, E. B. (2010). Effects of preschool parents' power assertive patterns and practices on adolescent development. Parenting: Science and Practice, 10(3), 157-201. doi:10.1080/15295190903290790

Bernier, A., Carlson, S. M., \& Whipple, N. (2010). From external regulation to self-regulation: Early parenting precursors of young children's executive functioning. Child Development, 81(1), 326-339. doi:10.1111/j.1467-8624.2009.01397.x

Caspi, A., Harrington, H., Milne, B., Amell, J. W., Theodore, R. F., \& Moffitt, T. E. (2003). Children's Behavioral Styles at Age 3 Are Linked to Their Adult Personality Traits at Age 26. Journal of Personality, 71(4), 495-513. doi:10.1111/1467-6494.7104001 
Cho, J., Kogan, S. M., \& Brody, G. H. (2016). Genetic moderation of transactional relations between parenting practices and child self-regulation. Journal of Family Psychology, 30(7), 780-790. doi:10.1037/fam0000228

Cipriano, E. A., \& Stifter, C. A. (2010). Predicting preschool effortful control from toddler temperament and parenting behavior. Journal of Applied Developmental Psychology, 31(3), 221-230. doi:10.1016/j.appdev.2010.02.004

Crossley, I. A., \& Buckner, J. C. (2012). Maternal-related predictors of self-regulation among low-income youth. Journal of Child and Family Studies, 21(2), 217-227. doi:10.1007/s10826-011-9465-0

Darling, N., \& Steinberg, L. (1993). Parenting style as context: An integrative model. Psychological Bulletin, 113(3), 487-496. doi:10.1037/0033-2909.113.3.487

Eisenberg, N., Zhou, Q., Spinrad, T. L., Valiente, C., Fabes, R. A., \& Liew, J. (2005). Relations Among Positive Parenting, Children's Effortful Control, and Externalizing Problems: A Three-Wave Longitudinal Study. Child Development, 76(5), 1055-1071. doi:10.1111/j.1467-8624.2005.00897.x

Hanley, S. J., \& Abell, S. C. (2002). Maslow and relatedness: Creating an interpersonal model of self-actualization.Journal Of Humanistic Psychology, 42(4), 37-56. doi:10.1177/002216702237123

Jabeen, F., Anis-ul-Haque, M., \& Riaz, M. N. (2013). Parenting styles as predictors of emotion regulation among adolescents. Pakistan Journal of Psychological Research, 28(1), 85105. 
Karreman, A., van Tuijl, C., van Aken, M. G., \& Dekovic, M. (2006). Parenting and SelfRegulation in Preschoolers: A Meta-Analysis. Infant and Child Development, 15(6), 561579. doi:10.1002/icd.478

LeCuyer, E. A., \& Swanson, D. P. (2016). A within-group analysis of african american mothers' authoritarian attitudes, limit-setting and children's self-regulation. Journal of Child And Family Studies, doi:10.1007/s10826-016-0609-0

LeCuyer, E. A., Swanson, D. P., Cole, R., \& Kitzman, H. (2011). Effect of African-and European-American maternal attitudes and limit-setting strategies on children's selfregulation. Research In Nursing \& Health, 34(6), 468-482. doi:10.1002/nur.20460

Lewin, A., Mitchell, S. J., \& Ronzio, C. R. (2013). Developmental differences in parenting behavior: Comparing adolescent, emerging adult, and adult mothers. Merrill-Palmer Quarterly, 59(1), 23-49. doi:10.1353/mpq.2013.0003

Maslow, A. H. (1943). A theory of human motivation. Psychological Review, 50(4), 370-396. doi: $10.1037 / \mathrm{h} 0054346$

Olivari, M. G., Tagliabue, S., \& Confalonieri, E. (2013). Parenting Style and Dimensions Questionnaire: A review of reliability and validity. Marriage \& Family Review, 49(6), 465-490. doi:10.1080/01494929.2013.770812

Osborne, A. F., Butler, N. R., \& Morris, A. C. (1984). The Social Life of Britain's Five Year Olds: A Report of the Child Health and Education Study. London: Routledge and Kegan Paul.

Pinquart, M., \& Kauser, R. (2017). Do the Associations of Parenting Styles With Behavior Problems and Academic Achievement Vary by Culture? Results From a MetaAnalysis. Cultural Diversity And Ethnic Minority Psychology, doi:10.1037/cdp0000149 
Piotrowski, J. T., Lapierre, M. A., \& Linebarger, D. L. (2013). Investigating correlates of selfregulation in early childhood with a representative sample of English-speaking American families. Journal of Child And Family Studies, 22(3), 423-436. doi:10.1007/s10826-0129595-Z

Ponitz, C. C., McClelland, M. M., Jewkes, A. M., Connor, C. M., Farris, C. L., \& Morrison, F. J. (2008). Touch your toes! Developing a direct measure of behavioral regulation in early childhood. Early Childhood Research Quarterly, 23, 141-158. doi: 10.1016/j.ecresq.2007.01.004.

Putnam, S. B., \& Rothbart, M. K. (2006).Development of short and very short forms of the Children's Behavior Questionnaire. Journal of Personality Assessment, 87, 103-113

Ramey, C. T., \& Ramey, S. L. (2004). Early Learning and School Readiness: Can Early Intervention Make a Difference?. Merrill-Palmer Quarterly, 50(4), 471-491. doi:10.1353/mpq.2004.0034

Razza, R. A., Bergen-Cico, D., \& Raymond, K. (2015). Enhancing preschoolers' self-regulation via mindful yoga. Journal of Child and Family Studies, 24(2), 372-385. doi:10.1007/s10826-013-9847-6

Reynolds, A. J., Richardson, B. A., Hayakawa, M., Lease, E. M., Warner-Richter, M., Englund, M. M., \& ... Sullivan, M. (2014). Association of a full-day vs part-day preschool intervention with school readiness, attendance, and parental involvement. JAMA: Journal of the American Medical Association, 312(20), 2126-2134. doi:10.1001/jama.2014.15376

Robinson, C. C., Mandleco, B., Olsen, S. F., \& Hart, C. H. (2001).The Parenting Styles and Dimensions Questionnaire. Handbook of family measurement techniques, 3, 319-321. 
Ryder, A.G., Alden, L., \& Paulhus, D.L. (2000). Is acculturation unidimensional or bidimensional?: A head-to-head comparison in the prediction of demographics, personality, self-identity, and adjustment. Journal of Personality and Social Psychology, $79,49-65$.

Sangawi, H., Adams, J., \& Reissland, N. (2016). The impact of parenting styles on children developmental outcome: The role of academic self-concept as a mediator. International Journal of Psychology, doi:10.1002/ijop.12380

Shaffer, D. R., \& Kipp, K. (2013). Developmental Psychology: Childhood and Adolescence. Belmond, CA: Cengage Learning.

Steinberg, L., Mounts, N. S., Lamborn, S. D., \& Dornbusch, S. M. (1991). Authoritative parenting and adolescent adjustment across varied ecological niches. Journal of Research on Adolescence, 1(1), 19-36.

Steinberg, L., Lamborn, S. D., Dornbusch, S. M., \& Darling, N. (1992). Impact of parenting practices on adolescent achievement: Authoritative parenting, school involvement, and encouragement to succeed. Child Development, 63(5), 1266-1281. doi:10.2307/1131532

Stokes, J., Pogge, D., Wecksell, B., \& Zaccario, M. (2011). Parent-child discrepancies in report of psychopathology: The contributions of response bias and parenting stress. Journal of Personality Assessment, 93(5), 527-536. doi:10.1080/00223891.2011.594131

Uji, M., Sakamoto, A., Adachi, K., \& Kitamura, T. (2014). The impact of authoritative, authoritarian, and permissive parenting styles on children's later mental health in Japan: Focusing on parent and child gender. Journal of Child and Family Studies, 23(2), 293302. doi:10.1007/s10826-013-9740-3 
Wanless, S. B., McClelland, M. M., Acock, A. C., Ponitz, C. C., Son, S., Lan, X., \& Li, S. (2011). Measuring behavioral regulation in four societies. Psychological Assessment, 23(2), 364-378. doi:10.1037/a0021768

Zarra-Nezhad, M., Kiuru, N., Aunola, K., Zarra-Nezhad, M., Ahonen, T., Poikkeus, A., \& Nurmi, J. (2014). Social withdrawal in children moderates the association between parenting styles and the children's own socioemotional development. Journal of Child Psychology 


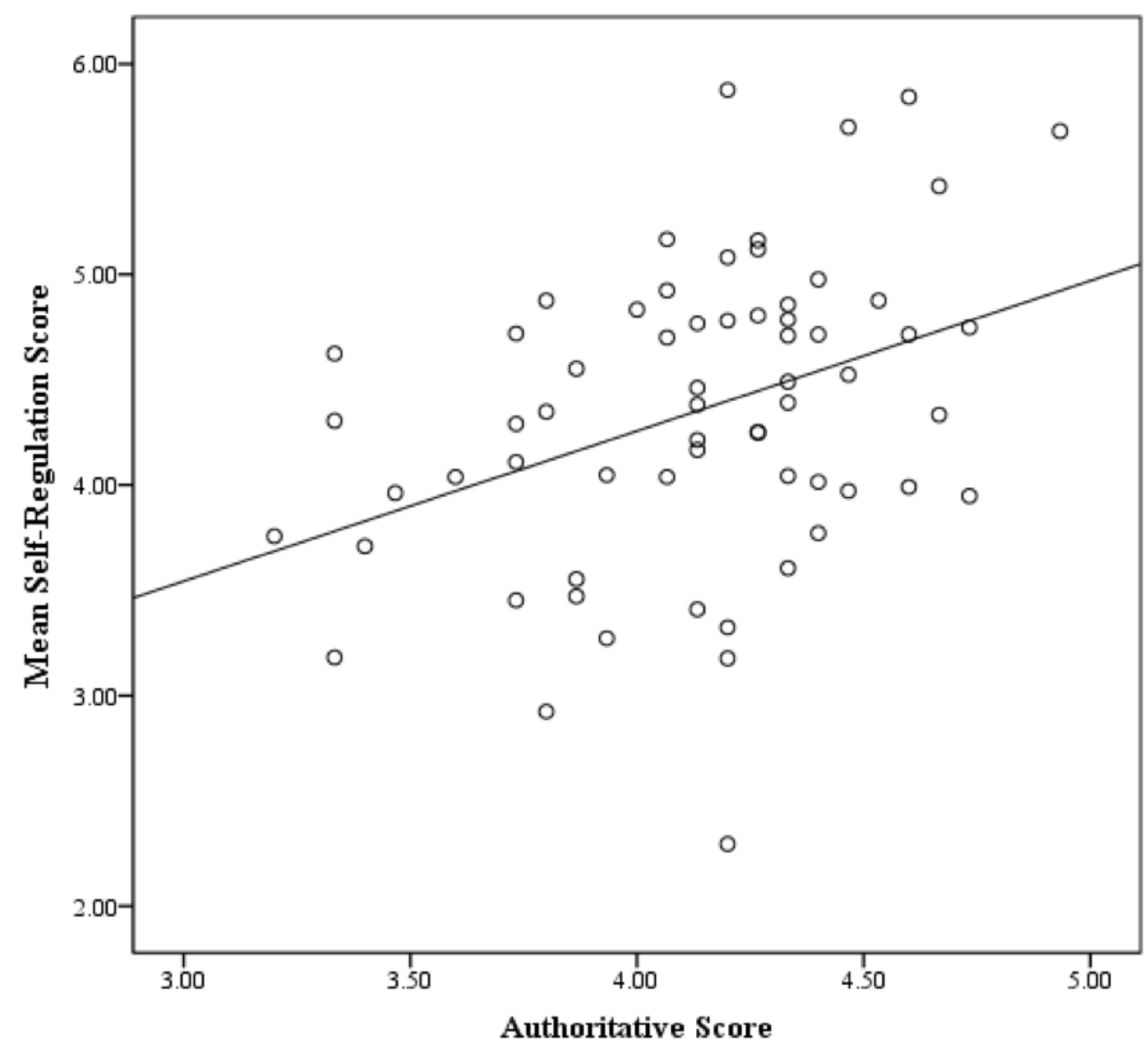

Figure 1.

Scatterplot of Self-Regulation and Authoritative Score Correlation 


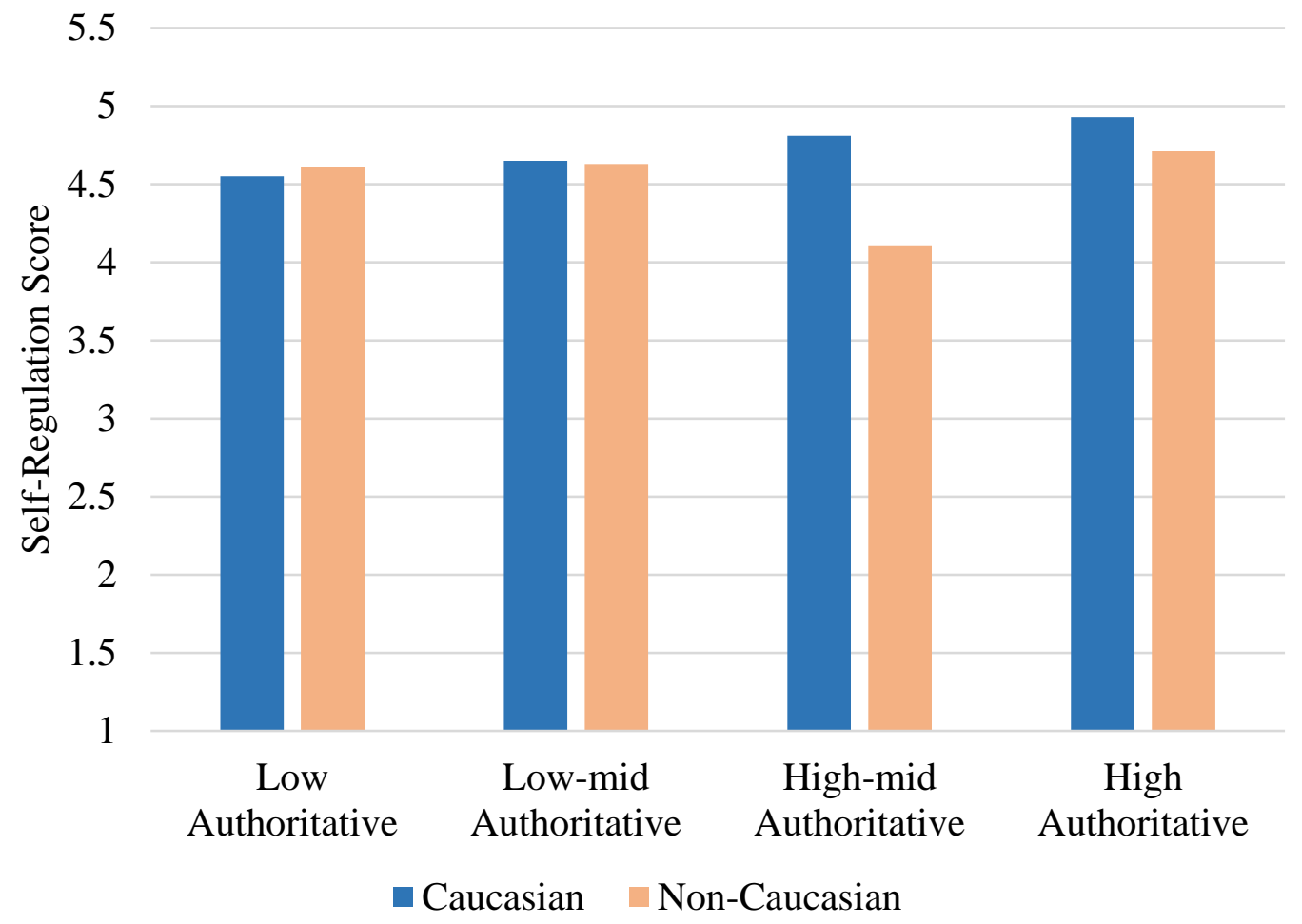

Figure 2.

Self-Regulation Scores by Parenting Style and Ethnicity 
Table 1.

Self-Regulation and Authoritative and Permissive Parenting Styles Correlations

\begin{tabular}{|c|c|c|c|c|c|}
\hline & Connection & Regulation & $\begin{array}{c}\text { Autonomy } \\
\text { Granting }\end{array}$ & $\begin{array}{l}\text { Authoritative } \\
\text { Score }\end{array}$ & $\begin{array}{l}\text { Permissive } \\
\text { Score }\end{array}$ \\
\hline $\begin{array}{c}\text { Self-Regulation } \\
\text { Score }\end{array}$ & .219 & $.315^{*}$ & $.330^{* *}$ & $.378^{* *}$ & $-.293^{*}$ \\
\hline Child Activity & .057 & .082 & .110 & .111 & -.175 \\
\hline Child Impulsivity & $.280^{*}$ & .231 & .241 & $.314^{*}$ & -.234 \\
\hline Child Focus & .054 & .144 & $.265^{*}$ & .219 & -.116 \\
\hline $\begin{array}{c}\text { Child Inhibitory } \\
\text { Control }\end{array}$ & .174 & $.408^{* *}$ & $.364^{* *}$ & $.422^{* * *}$ & $-.273^{*}$ \\
\hline Child Reactivity & .216 & $.259^{*}$ & .207 & $.288^{*}$ & $-.258^{*}$ \\
\hline
\end{tabular}

** Correlation is significant at the 0.01 level (2-tailed).

* Correlation is significant at the 0.05 level (2-tailed). 
Table 2.

Self-Regulation and Authoritarian Parenting Style Correlations

\begin{tabular}{lcccc}
\hline & $\begin{array}{c}\text { Physical } \\
\text { Coercion }\end{array}$ & $\begin{array}{c}\text { Verbal } \\
\text { Hostility }\end{array}$ & $\begin{array}{c}\text { Non- } \\
\text { Reasoning/ } \\
\text { Punitive } \\
\text { Action }\end{array}$ & $\begin{array}{c}\text { Authoritarian } \\
\text { Score }\end{array}$ \\
\hline Self-Regulation Score & -.142 & $-.247^{*}$ & $-.332^{* *}$ & $\mathbf{- . 3 2 0}^{* *}$ \\
Child Activity & .021 & .088 & -.107 & .007 \\
Child Impulsivity & -.027 & -.138 & -.123 & -.133 \\
Child Focus & -.113 & -.220 & -.173 & -.228 \\
Child Inhibitory & & & & \\
Control & -.111 & -.227 & $-.473^{* *}$ & $-.359^{* *}$ \\
Child Reactivity & & & & \\
\hline
\end{tabular}

** Correlation is significant at the 0.01 level (2-tailed).

* Correlation is significant at the 0.05 level (2-tailed). 